\title{
Cultivating Communities of Practice on a National SCALE TO SUPPORT THE SHIFT TO REMOTE EDUCATION
}

\author{
Stephen Mattucci ${ }^{1,2}$, Elizabeth DaMaren ${ }^{1}$, Cori Hanson ${ }^{1,3}$, Rubaina Khan ${ }^{1,3}$, and Renato Alan Bezerra \\ Rodrigues ${ }^{1,4}$ \\ ${ }^{1}$ E-CORE/CIEL Project, ${ }^{2}$ York University, ${ }^{3}$ University of Toronto, ${ }^{4}$ University of Manitoba \\ mattucci@yorku.ca, elizabeth.damaren@gmail.com, cori.hanson@utoronto.ca, rubaina.khan@ mail.utoronto.ca,
} bezerrar@myumanitoba.ca

\begin{abstract}
Educational innovations and just-in-time supports spread more quickly through social networks than through traditional dissemination avenues. Therefore, in coordinating national level support efforts for the shift to online and remote learning during the COVID-19 pandemic, one of the principal strategies of the Engineering Collaboration for Online and Remote Education (E-CORE/CIEL) Project was to develop national Communities of Practice (CoPs) to foster connections between instructors. Using an autoethnographic process, this reflective paper aims to synthesize the learnings from the team working to cultivate these CoPs.

The analysis of the reflections provides insight on: the needs of the Canadian community of engineering educators during a year of remote education, the perceived benefits of engaging in CoPs, considerations for cultivating CoPs in different contexts, and recommendations for future cross-institutional CoP efforts.
\end{abstract}

Keywords: Communities of Practice, Online and remote education, National support, Reflection, Autoethnography, Learning networks, Social Learning

\section{MOTIVATION AND BACKGROUND}

Best practices in teaching, educational innovations, perspectives for overcoming challenges, and just-in-time supports spread more quickly through direct connections between people than when they are disseminated through the literature or formal public discourse [1]. In both academic and industry settings, Communities of Practice (CoPs) provide individuals with the opportunity to improve their practice with the support of others by providing a structured group environment that allows for strong connections to form [2-5]. Therefore, well-connected networks and strong communities can add resiliency to an ecosystem in times of disruption or systemic challenges.

The underlying $\mathrm{CoP}$ theory is that "engagement in social practice is the fundamental process by which we learn and so become who we are" [6]. CoPs are built around three main characteristics: the domain of knowledge they are centred on, the community of people that comprise the group, and the practice that members share and innovate around $[6,7]$. The structure of CoPs varies greatly. A CoP can be run by members $[3,8]$ or external facilitators [9]. The frequency of the meetings can vary from only a few times a year to multiple times per month, and they can be implemented on any scale, from national to departmental. Incentivization mechanisms for participation in CoPs range from formal recognition from institutions for participation [9] to more intrinsic motivators such as the opportunity to network, learn from others, or engage in professional development.

While their structure may differ, there are common values derived from participation in CoPs. They provide a space for members to come together and collaboratively work on large challenges, while also providing safe spaces for members to reflect on their own practices [9]. They can be used to coordinate the generation of resources and the accumulation of collections of knowledge and best practices [2]. CoPs allow members to easily access the collective knowledge and expertise of the group [7], as well as rely on others for professional or emotional support. These benefits position CoPs as a powerful mechanism to overcome a system-wide challenge, such as shifting to remote education during the COVID-19 pandemic.

Canadian Engineering Education organizations, initiatives, and leaders came together in May 2020 at the Engineering Deans Canada meeting to generate a collaborative approach to provide urgent support to instructors at a national scale during the pandemic. This included most deans from engineering faculties nationwide, and representatives from the Canadian Engineering Education Association (CEEA-ACEG) [10], the Engineering Graduate Attribute Development (EGAD) Project [11], the Canadian Engineering Education Challenge (CEEC) [12], and the Engineering Change Lab [13]. The result was the pooling of initiative resources, and the formation of the Engineering Collaboration for Online and Remote Education (E-CORE/CIEL) Project [14]. The project was tasked with coordinating national-level support efforts for the shift to online and remote learning, while prioritizing urgency and agility during a time of rapidly changing uncertainty. The project was framed using a logic 
model approach around three areas of focus: disseminating curriculum and pedagogy (e.g. resource curation, workshops, etc.), reward structures recognizing educational contributions (i.e. engagement incentives), and connecting educators to each other (i.e. networks and communities). One of the principal strategies within this final frame was to develop national CoPs to foster connections between instructors so that they could better support one another as they adapted to remote teaching. Given the extensive potential benefits of CoPs, they were positioned to be a central support avenue.

A CoP facilitator team was established, including three engineering education graduate students, and the two ECORE/CIEL project coordinators. They began hosting CoPs for engineering educators across Canada in June 2020 in two domains and expanded to CoPs covering seven domains in September 2020 as academic terms began. The domains included: assessment, online labs, student experience, design instructors, first-year instructors, nontechnical course instructors, and teaching assistants. Several biweekly CoP sessions saw substantial engagement over the summer term, followed by varying levels of engagement within each group as the Fall semester progressed.

With a priority around urgency and agility, the CoPs need to continuously shift to support the needs of the community. To gain a more comprehensive understanding of the factors influencing the CoPs, the facilitation team underwent an autoethnographic process to reflect on the progress thus far. The primary goal of this work is to synthesize the learnings from the team working to cultivate national CoPs through ground level experience and aspirational narratives. This work will provide insight and recommendations for the evolution of CoPs in the national context, which can be applied to a variety of communitybuilding activities and settings.

\section{FRAMING AND PROCESS}

\subsection{Theoretical Frameworks}

The theoretical frameworks underpinning this work are social constructivism, communities of practice, social network theory, and reflection-in-action. The overarching concept affiliated with each theory is the idea of social learning, where learning primarily occurs from interactions between people [15].

Social Constructivism. Social constructivism theory posits that knowledge, understanding, significance, and meaning are developed cooperatively between individuals [16]. In this research, we came together to collectively build our understanding of the role and impact of CoPs in the Canadian Engineering Education space. We each bring our own experiences to make broader meaning together.

Communities of Practice. Communities of Practice are not only the subject of this work, but also a theoretical perspective on knowing and learning. CoPs are "formed by people who engage in a process of collective learning in a shared domain or human endeavor" [17]. CoPs can be intentional and explicit, or unintentional and tacit. The term came from research on apprenticeship, where the community of practitioners served as a "living curriculum" for the learners. This concept can be expanded by considering a community as a group of people who have various identities as learners and practitioners. Thus, all members of a CoP are learning as their practice actively evolves. This research focuses on CoPs as a method to generate learning within the Engineering Education community in Canada in sub-groups, and at the meta-level, as facilitators improve their practice by learning from one another.

Social Network Theory. Social Network Theory suggests that relationships and connections between individuals can have a significant impact on their actions and behaviours [18]. Particularly in the teaching domain, learning occurs through significant conversations characterized by privacy, mutual trust, and intellectual intrigue [1]. These networks can be a powerful mechanism for influencing change processes across boundaries and organization structures [18]. The cultivation of CoPs was intended to build and strengthen these connections throughout the system to allow increased flow of expertise within the system, ultimately to enable instructors to better support each other.

Reflection-in-action. Reflection-in-action involves active reflection on one's actions while they are doing them [19]. This approach involves practitioners (and researchers) critically evaluating processes as they unfold and making adjustments. This research involves reflectionin-action, as we continued the organization and facilitation of the CoPs throughout the research process.

\subsection{Methodologies}

The action research approach builds upon the reflectionin-action theory. It involves adaptations in the process as each team member continues to research, learn, and develop their own practice as facilitators/coordinators with the ongoing E-CORE/CIEL project [20]. This parallel research project provides opportunities for on-the-go evaluation, as reflections and learnings can be immediately integrated back into project operations.

The narrative-inquiry autoethnography approach allows us, the researchers, as a collective, to examine significant experiences from our own perspectives having lived through them [20]. At least one team member was present and experienced each CoP meeting since the initiative began. Coupled with narrative inquiry and reflective writing, we were each able to write about our own experiences to generate a data set for analysis to represent our collective views. Qualitative thematic analysis was used to iteratively generate common codes, to then be grouped around common themes as the main areas of interest for this work. 
The five authors comprised the team facilitating the CoPs, including one full-time project coordinator, a project advisor, and three CoP facilitators. All members had experience running E-CORE/CIEL CoPs, most had other experience with formal CoPs, and others now realize the implicit CoPs they had participated in the past. Except for one project coordinator, who had run E-CORE/CIEL CoPs in the summer of 2020, all other members were running CoPs during the writing of this paper.

\subsection{Autoethnographic Process}

To construct the reflection, the team developed openended reflective prompts according to a semi-structured interview framework [21] with the intention of providing enough scope and context to yield responses that capture different perspectives on similar experiences. Prompts progressed through three stages of exploration: i. context and background, ii. lived experience, and iii. making meaning. All five reflections were then coded through an inductive thematic analysis by each author individually, using qualitative analysis software (Dedoose, v. 8.3.19). The authors then met to build consensus and merge their individual code lists and create a unified codebook before conducting a second iteration of individual coding. Key themes were identified from groupings of the final code list to inform the analysis [Table 1].

\section{REFLECTION ANALYSIS AND DISCUSSION}

Key ideas from the reflections were grouped and organized into thematic sections to provide insight on: the perceived benefits of engaging in CoPs for individual participants and engineering faculties, considerations for cultivating CoPs in different contexts, and recommendations for future cross-institutional CoP efforts.

\subsection{Ideal State}

Wenger [22] emphasizes that the domain of interest, the community, and the practice are the crucial characteristics of a CoP. These elements of the $\mathrm{CoP}$ are actively developed as members participate which also gives meaning to their actions. Through joint activities in the community, members share a domain of interest or competence. The practice is the specific focus of a $\mathrm{CoP}$ around which the community develops and maintains its core knowledge.

CoPs form and thrive when community members convene around a shared domain of interest. Amidst the pandemic, instructors had to quickly adapt their courses into an online format. As facilitators, we observed that instructors were inspired to participate when they noticed that strategies and ideas shared in the meetings were something that they could take back to their practice. Also, in the context of the pandemic, instructors were overloaded with instructional and pedagogical strategies from their institutions and colleagues. Through listening and probing questions, CoP members were able to learn and gather confidence to try out strategies that their fellow members had successfully implemented in their courses.

Table 1: Description of key themes from analysis.

\begin{tabular}{|c|c|}
\hline Theme & Description / Meaning \\
\hline 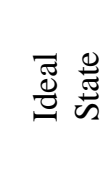 & $\begin{array}{l}\text { Compares how E-CORE/CIEL CoPs were } \\
\text { related to the theoretical concept of CoPs } \\
\text { and the facilitators' perception of the ideal } \\
\text { condition for CoPs to flourish. }\end{array}$ \\
\hline 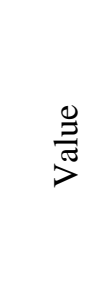 & $\begin{array}{l}\text { Examines the facilitators' perceived benefits } \\
\text { for members through participation in CoP as } \\
\text { well as perceptions of what value } \\
\text { participants place on CoPs. These } \\
\text { perceptions are derived from the literature } \\
\text { on CoPs, previous experiences as members } \\
\text { of CoPs, and observations as facilitators. }\end{array}$ \\
\hline 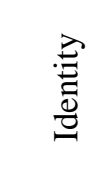 & $\begin{array}{l}\text { Explores how participants see themselves } \\
\text { and their multiple roles, and how this relates } \\
\text { to motivation and macro- and micro-cultures } \\
\text { that exist in this space. }\end{array}$ \\
\hline 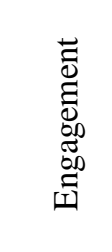 & $\begin{array}{l}\text { Considers how participants engage with the } \\
\text { CoP in all its forms, including attending and } \\
\text { participating in meetings. Also discusses the } \\
\text { importance of active vs. passive } \\
\text { engagement, and the barriers for engaging in } \\
\text { discussions. }\end{array}$ \\
\hline 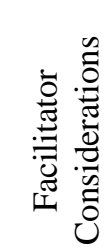 & $\begin{array}{l}\text { Covers reflections on the main facilitation } \\
\text { and administrative concerns of running a } \\
\text { CoP. This includes the role of a facilitator } \\
\text { and their activities, structuring of the actual } \\
\text { CoPs sessions, communication strategies, } \\
\text { and logistics considerations. }\end{array}$ \\
\hline
\end{tabular}

The communal activities in the CoP meetings, such as discussions, resource sharing, and problem-solving opportunities, created social fabric that enabled learning as a collective. As we progressed through the term, regular members started to feel more comfortable in sharing honest opinions and asking others for ideas. This sense of community led to increased interactions and encouraged a willingness to provide suggestions to others. Hence, over time, the members were able to feel that they could trust others for useful advice and be comfortable in sharing their concerns.

The instructors in the E-CORE/CIEL CoPs are practitioners in the domain of interest. The meetings provided them the space to share resources and ideas that others could take back to their practice. Often, we saw members offering perspectives on an issue based on their personal lived experiences. These frequent and meaningful 
conversations between members broadened the collective knowledge of the membership.

We noticed the CoPs have the potential to connect people who might not otherwise have had the chance to interact, frequently or at all. There was an overwhelming sense that the pandemic had exacerbated the already isolated environment of academia. We aspired for the CoP meetings to allow members to connect with colleagues across Canada and to reduce the isolation instructors were feeling in implementing online learning strategies. This experience was augmented by the nature of the CoPs, which is to provide a shared context for members to communicate through sharing of resources, narratives, and personal experiences in a way that constructs meaning.

In addition, instructors face issues in their teaching that are complex and multi-faceted. We noticed the CoP meetings provided the space to revisit complex problems across weeks. Also, complex issues can promote dialogue that requires implicit knowledge that can only be shared through deep conversations, and diverse perspectives. We observed a successful CoP to have a regular membership and an overt willingness to help fellow colleagues overcome challenges in online teaching and related issues.

\subsection{Value}

The facilitators for the CoPs came into this project with their own predetermined ideas of the potential value of the groups. We decided to be part of this initiative because we all saw potential value in a shared space for engineering educators to discuss and reflect on their teaching practices as a community. This is seen in how many of the facilitators believed that a supportive community providing the opportunity for situated learning would lead to improved practice through a variety of valuable outcomes for the CoP members and the greater community of engineering educators. These preconceived values align with Wegner and colleagues' [22] definition of value creation in communities and networks which defines five levels of value which they call cycles:

Cycle 1. Immediate value: Activities and interactions

Cycle 2. Potential value: Knowledge capital

Cycle 3. Applied value: Changes in practice

Cycle 4. Realized value: Performance improvement

Cycle 5. Reframing value: Redefining success

However, in running the E-CORE/CIEL CoPs, not all levels of value were realized.

In reflecting on our experiences facilitating the CoPs so far, we observed immediate, potential and to a lesser extent applied value. Immediate value was seen as members of the CoPs vocalizing their appreciation for the community existing and repeated attendance from some members. The interactions between members at meetings was perceived as a "big win" for all CoPs. We also noted that some members did come to meetings with questions and issues which were solved at meetings through discussion of teaching practices, tools and sharing of experiences. This could be categorized as potential value, since there was a sense that, for those who joined the CoP, there was important information being shared, particularly around teaching online for the first time. Some members indicated they planned on taking what they had learned at CoP meetings and using this in their teaching, and in one CoP a member returned to the group and reported back on ideas from the CoP that they had implemented, which shows the possibility and actualization of applied value.

There was no indication from our reflections that realized value or reframing value were occurring in the CoPs. We have not noted any significant evidence that the CoPs have resulted in improved performance for members or that they have led any individual members or CoPs as a group to redefine success within their given domains. This could be because most CoPs have not seen consistent engagement from the same set of members, because facilitators have not yet explicitly asked for evidence from participants, and/or because these changes in value and behavior take more time than the other levels. This could be an area for future assessment or research.

We also saw value as a potential barrier to engagement with the CoPs. There are many barriers to engagement, which are further discussed below; however, we as facilitators questioned whether these would be less significant if engineering educators saw more value in CoPs. It appears that in this space during a time of urgency, the value of being connected within a community, especially as it pertains to the higher levels of value, is not explicit enough to be intentional. Generally, we saw an evident need for community from instructors; however, it was rarely articulated as a reason for joining. We did observe a peak in perceived value from participants in the summer when many instructors were quickly shifting to online learning and this continued for some CoPs throughout the Fall.

We noted a potential barrier in the lack of value placed on these types of professional development activities in engineering education. This could be due to a lack of extrinsic value placed on these kinds of activities. We believe there is perceived value in CoP membership and engagement from Engineering Deans Canada, as many provided funding for the E-CORE/CIEL Project. However, we reflected that we were unclear as to whether faculty members could or would include CoP membership on activity reports, or whether these could be used for career advancement. Therefore, there seems to be a lack of perceived value for these activities compared to other professional development activities that result in publications and/or can be listed under service. Thus, CoPs in this context seemed to rely on participants differentiating the value for themselves.

\subsection{Identity}

Within COPs, the identity of each participant plays a critical role, as it can influence expectations around value 
and engagement, and drive culture. Identity is integral within social learning theory, as it drives participation or non-participation, and shapes the meanings that define our communities and our sense of belonging [6]. It is unsurprising that these issues were prevalent within our reflections.

We noticed engagement trends based on whether the CoP was focused on the participants' identities (e.g. firstyear, design, lab instructors) vs. topics (e.g. student engagement, non-technical courses). All 5 facilitators noted in their reflections that identity-based CoPs had greater and more sustained engagement. One element that could explain this difference is pre-existing communities. Participants may know each other from established communities (e.g. CEEA Special Interest Groups, attending similar events in the past, etc.), and the CoP is another avenue to convene. Those who share similar identities likely also share similar experiences and challenges, making it easier to generate discussion where most people can contribute.

Topic-based CoPs appear to be valuable in other ways. When there is a sense of urgency and need for solutions to a common challenge, these CoPs had greater engagement as people convened around a sense of need to search for immediate solutions. For example, during the summer of 2020 when instructors were shifting to remote instruction, everyone had an urgent need for adapting assessments. This idea is supported by the high engagement in related E-CORE workshops hosted during the summer. However, when a CoP based on this topic was established in the Fall, the engagement was much less as it seemed there was less of an urgent need for community discussions.

Identity also plays a role within the CoP linked to participation and behaviour. As new members join, most are unfamiliar with this approach. They likely will not understand what role they play within the group and how to engage, and when trying to cultivate CoPs, it is challenging to find participants to model the behaviour. When participants can easily identify their role within a $\mathrm{CoP}$ in relation to other members, it likely contributes to more sustained engagement. Those who do not identify with the CoP will likely be less likely to return.

Identity can also be a barrier, considering the primary target for participants are engineering faculty members. Engineering typically fosters positivistic ways of thinking, where there are objective truths - 'right' and 'wrong' ways of doing things - this culture is not as open towards supporting discussion as a means of learning and negotiating 'grey' areas. Despite realizing the importance of certain topics (e.g. student mental health), faculty may not see this as their responsibility. As one facilitator put it, "they see this as more of a staff role (to look out for student mental health) and see this outside their scope. Not that they don't care but that their job is to teach technical material". Further, identities are closely affiliated with extrinsic motivators (e.g. faculty members and tenure and promotion criteria), which relies on participants to differentiate the value for themselves (Section 3.2: Value).

\subsection{Engagement}

Member engagement is what keeps a CoP alive and healthy. To flourish, CoPs need a base of core and consistent members upon which the "community" aspect is built, creating a sustainable environment for members to engage in improving their "practices." In our view, engagement in a CoP can take many forms, including both synchronous and asynchronous forms. In our reflections, we noticed that most of the engagement in the CoPs happens synchronously, during the meetings, in the form of attendance, sharing resources, collaborating to create new resources and strategies, building on others' thoughts and viewpoints, and showing concern for each other's' well-being. We saw occasional asynchronous engagement where participants connected outside of the meetings, usually in the form of emails and following up on resources mentioned in the meetings. However, asynchronous engagement between members is challenging to track.

In meetings, there are two types of participants: those who engage actively, and those who prefer to stay passive. Although we recognize and welcome members who prefer to just listen to and passively learn from the conversations, we believe that active participants are crucial for the productivity and effectiveness of the CoPs. Being active does not mean only presenting solutions and sharing resources or experiences. Those who bring issues for discussion or seek advice and specific resources are also actively participating, since they move the conversation forward, prompt discussions, and show effort towards one of the main goals of a CoP: improving their practices.

We experienced situations where participants showed up and wanted to "just listen." In these cases, we, as facilitators, had to be the ones driving the conversation and prompting those few active members, which can give them a sense of unidirectional value; they are giving, but not receiving. We know as facilitators that one of our responsibilities is to manage the flow of the conversation, but we all agree that the discussions are more authentic and valuable when the issues and questions naturally emerge from the community. However, lack of active engagement was not seen as a common issue since, in most meetings, we found that most participants were actively engaged.

We observed a few potential barriers for actively engaging during the CoP meetings. First, self-perceived lack of expertise can cause participants not to voice their opinions or experiences, since they believe that they have nothing of value to contribute or that they are wrong. A second barrier can be the lack of awareness of what a CoP entails. There were instances where new members joined the meetings because "they wanted to see what this is about." That is when having active, core members become even more crucial - they can model behavior by showing what a CoP is about [Section 3.3: Identity]. Lastly, we 
believe that for some members to actively engage, especially when it comes to sharing their experiences, issues and resources, there needs to be a connection and trust in the other participants. That is where the building community becomes fundamental for improving practice.

\subsection{Facilitation Considerations}

For the E-CORE/CIEL CoPs, the facilitators were the driving force behind the groups. As a result, considerations on the role and key activities of the facilitators were a common theme in the reflections. The facilitators met on a weekly basis to discuss activities and facilitation strategies, but each was encouraged to take ownership to decide how to structure their own CoPs.

Our reflections revealed a common progression of structuring discussions. In early CoP meetings, facilitators would determine a conversation topic and prepare a set of discussion prompts ahead of meetings. These prompts would ensure the facilitator could keep the conversation going, oftentimes established a way to break the ice with group members and encouraged focused responses from participants. However, intentional structuring of the conversations seemed to become less necessary as groups became more familiar with each other. We saw that community members would develop their conversation organically, and a reduced need for facilitator interjection.

While prompts provided a way to help get the conversation started and could impart the facilitator with a sense of confidence in having them ready in case conversation dwindled, there were downfalls to this prompt approach. One author reflected that prompts made the CoP sessions feel like a question-and-answer session. Instead, improvising and asking guiding questions as new topics arose enabled the conversation to flow smoother. Some facilitators also found that allowing the participants to direct the conversation beyond prompts often led to repetition in topics, though we believe that was likely due to common concerns (e.g. assessments, labs), and by allowing groups to return to topics, it allowed for new perspectives, thoughts, and solutions to be proposed. Additionally, some facilitators found that with this openended structure, conversations did not necessarily seem to have an 'outcome', though we are not sure if a central outcome is needed. Anecdotally, we received feedback that participants were finding value in the sessions as we had structured them. However, other discussion structuring methods, such as workshop-style or show-and-tell sessions, could be further explored as options for facilitation strategies to increase tangible outcomes.

Outside of the CoP sessions, the facilitation team was also responsible for the communication and marketing strategy behind the groups. We found that spreading the word about these groups was challenging, not necessarily in the communication channels, but rather in the content of those communications. The concept of a $\mathrm{CoP}$ can be abstract to many people, and when the value is not immediately obvious, we believe effective communications must make the value more explicit for potential participants. Marketing campaigns can be used to build awareness around the purpose and value of CoPs, potentially helping to drive engagement. This can be especially useful in national contexts, where facilitators do not necessarily have pre-established networks of people to invite to sessions.

In addition to the challenge of communicating the value of the CoPs, we also found it challenging to determine the optimal frequency and types of content to send out to generate engagement in the groups. We had a variety of communication channels, including a regular biweekly update email for the project, mentions at various events and webinars that the E-CORE/CIEL Project hosted, a web page, and a newsletter for CoP participants. We aimed to make information about these groups as accessible and clear as possible but, considering how many new participants were unsure of what type of meeting they were joining, it is possible the concept of CoPs was not well established within the broader community. We are gathering feedback to inform future efforts, as the communication strategy is critically important.

Scheduling the meetings of the groups was challenging. Consistent biweekly meeting times were decided upon to provide a regular schedule that participants could expect, but it was difficult to find times when most members were available. The use of scheduling tools was only partially successful, both due to a lack of response from the participants, and their busy schedules. As a team, we knew it was hard for people to prioritize time for meetings, especially if they do not see the value in the sessions or do not have any extrinsic motivators to engage (Section 3.2: Value). Given the national contexts of these groups, time zones also posed an issue, as it limited the window when members on both the East and West coasts would be able to engage (typically 12:30 pm - 5:30 pm NL or 8:00 am 1:00 pm PT). Additionally, changing schedules each semester meant either finding new times, or having some members unable to attend meetings.

Zoom fatigue, commonly referred to during the pandemic as exhaustion due to quantity and frequency of online meetings [23], was also a barrier to engagement that was of concern to all facilitators. While zoom fatigue and lack of bandwidth are issues that cannot be directly influenced by CoP facilitators, it is an important consideration in why engagement may lower over time. As facilitators, we can focus on making the CoP sessions highly engaging with emphasis on important topics for instructors so that if they are able to find time to come to a session, they are deriving value from it.

\section{IMPLICATIONS}

The lessons learned provide opportunities to inform the evolution of CoPs in the national context, while also being 
applicable to other community-building initiatives. The insights from our reflections are grouped into relevant contexts. These learnings, specifically those around the scheduling, communication, and facilitation strategies, will be utilized in restructuring the E-CORE/CIEL CoPs to increase their value for the community moving forward.

\subsection{Scheduling Logistics}

Establishing a mutual meeting time can be particularly challenging when participants are busy, and associated with different departments, institutions, or time zones. Scheduling tools can be utilized to gather input to optimize the meeting time. The tool must be effective in both its utility, and ease of use. Consistent meeting times on a regular basis also help to establish a sense of regularity.

We noticed CoPs that aligned with existing communities tended to have more participants, with more active engagement. One strategy could be to shift efforts to better support and strengthen these existing communities, since they likely have different needs than a CoP in early formation stages.

\subsection{Communication Strategies}

An intentional communication strategy using multiple channels can be used to build awareness and as a tool in promoting engagement in the groups. This is an area that requires continuous iteration as circumstances change. A balance is required between keeping participants informed (both active and potential), while avoiding exhausting people with unwanted messaging.

We noted that many participants attended CoPs without fully understanding the purpose. There were likely even more educators who did not attend for the same reason. One potential strategy could involve adjusting branding away from abstract "CoP" terminology and more towards language which promotes accessibility and value.

\subsection{Meeting Structure and Facilitation}

Guiding prompts can help to provide structure or a starting point in conversations while allowing participants to steer the conversation based on their interests and needs. This invites engagement and ensures participants derive value from the conversations. Session structure could be adapted for topic-focused CoPs to emphasize a common goal or output, such as 'show-and-tell' sessions. This could potentially also draw engagement from instructors interested in learning more about specific approaches.

\subsection{Sustainability}

Universities' leadership support can help to ensure a CoP's sustainability by encouraging instructors to participate, maintaining the incentives to run the meetings, and motivating joint efforts to create Canada-wide engineering education networks and research hubs.
The perception and value of CoPs by engineering educators could be a barrier for engagement. A stronger sense of community may be required for realizing and reframing value to be achieved [24]. Despite the lack of consistent engagement among repeat members in some CoPs, we feel they have had an immediate impact for the community. However, this can be challenging to evaluate, and is mostly informed through anecdotal evidence. For ongoing and higher levels of value to be achieved, a more sustained community with deeper connections between members is likely needed. Further research into the area of CoPs on national or other inter-institutional scales would be beneficial to further investigate the critical elements of CoPs that allow them to be sustainable in the longer term.

\section{CONCLUSiONS}

Establishing national CoPs was a central strategy of the E-CORE/CIEL Project to support the national engineering education community in shifting to remote teaching during the COVID-19 pandemic. To synthesize learnings, the facilitator team underwent an autoethnographic reflection process.

As facilitators, we found CoPs to be valuable when members of the community convene frequently, trust their colleagues to help with challenges they are facing, and exchange curated resources to expand the knowledge of their practice. To flourish, CoPs need a consistent membership to build the "community" aspect, and active engagement for members to interact and improve their "practice." Participant identities - with respect to both their institutional roles and culture, and role within the $\mathrm{CoP}$ - are critical factors that influence engagement and behaviour. The facilitation of CoPs involves scheduling challenges, implementing an intentional communication strategy, and providing structure to ensure discussions are valuable.

These insights will inform the evolution of the CoP approach at the national scale to continue to build and strengthen the community. A stronger community is better equipped to handle challenges in both the short- and longterm.

\section{Acknowledgements}

The E-CORE/CIEL Project is currently funded by 23 deans of faculties of engineering from the following institutions: Carleton University, Dalhousie University, École de technologie supérieure, École Polytechnique de Montréal, Lakehead University, Laurentian University, McGill University, Memorial University of Newfoundland, Queen's University, Royal Military College of Canada, Ryerson University, Université de Moncton, Université de Sherbrooke, University of British Columbia, University of Calgary, University of Manitoba, University of Ottawa, University of Regina, University of Saskatchewan, University of Toronto, University of 
Waterloo, University of Western Ontario, University of Windsor, and York University.

\section{References}

[1] Torgny Roxå and Katarina Mårtensson, "Significant conversations and significant networks - exploring the backstage of the teaching arena," Studies in Higher Education, vol. 34, no. 5, pp. 547-559, 2009, DOI: $10.1080 / 03075070802597200$

[2] Etienne Wenger, Richard McDermott, and William M. Snyder, Cultivating Communities of Practice: A Guide to Managing Knowledge. Boston, MA: Harvard Business School Press, 2002, 316 pp.

[3] Alexey Leontyev, Justin B. Houseknecht, Vincent Maloney, Jennifer L. Muzyka, Robert Rossi, Catherine O. Welder, and Leyte Winfield, "OrganicERs: Building a Community of Practice for Organic Chemistry Instructors through Workshops and Web-based Resources," Journal of Chemical Education, vol. 97, no. $1, \quad$ pp. 106-111, 2019, https://doi.org/10.1021/acs.jchemed.9b00104

[4] Trisha Parsons, Deborah Tregunno, Mala Joneja, Nancy Dalgarno, and Leslie Flynn, "Using graphic illustrations to uncover how a community of practice can influence the delivery of compassionate healthcare," Medical Humanities, vol. 45, no. 1, pp. 381-387, 2019.

[5] M. Fung-Kee-Fung, R. P. Boushey, J. Watters, R. Morash, J. Smylie, C. Morash, C. Degrasse, \& S. Sundaresan, "Piloting a regional collaborative in cancer surgery using a "community of practice" model," Current oncology, vol. 21, no. 1, pp. 27-34, February 2014.

[6] Etienne Wenger, Communities of Practice - Learning, Meaning, and Identity. New York, NY: Cambridge University Press, 1998, 318 pp. \{ISBN: 978-0-52166363-2\}

[7] Russell Pimmel, Ann F. McKenna, Norman L. Fortenberry, Brian Yoder, and Rocio C Chavela Guerra, "Faculty Development Using Virtual Communities of Practice". in 2013 ASEE Annual Conference \& Exposition (Atlanta, GA; 23-26 June 2013), 17 pp., 2013.

[8] Gilbert Probst and Stefano Borzillo, "Why communities of practice succeed and why they fail," European Management Journal, vol. 26, no. 5, 2008, pp. 335-347, ISSN 0263-2373, https://doi.org/10.1016/j.emj.2008.05.003.

[9] Jacquelin McDonald and Cassandra Star, "The challenges of building an academic community of practice: An Australian case study" in Engaging Communities, Proc. 31 ${ }^{\text {st }}$ HERDSA Annual Conf., (Rotorua, New Zealand; 1-4 July 2008), 10 pp., 2008.

[10] Canadian Engineering Education Association Association Canadienne de L'Éducation en Génie (CEEA-ACEG): https://ceea.ca/about-us/

CEEA-ACEG21; Paper 058

University of Prince Edward Island; June $21-23,2021-8$ of 8 -
[11] Engineering Graduate Attribute Development (EGAD) Project: https://egad.engineering.queensu.ca/

[12] Brian Frank, Bob Brennan, Laurent Mydlarski, Stephen Mattucci, and Deena Salem, "A networked social change lab approach to re-imagining engineering education" in Proc. CEEA Canadian Engineering Education Conf., CEEA18, (Vancouver, BC; 3-6 June 2018), 8 pp., 2018.

[13] Engineering Change Lab: https://www.engineeringchangelab.ca/

[14] Engineering Collaboration for Online and Remote Education (E-CORE) / Collaboration pour L'Ingénierie Enseignée en Ligne (CIEL) Project: https://ceea.ca/about-e-core/

[15] Albert Bandura, Social Learning Theory. New York, NY: General Learning Press, 1971.

[16] L.S. Vygotsky, Mind in society: The development of higher psychological processes. Cambridge, MA: Harvard University Press, 1978.

[17] Etienne Wenger, Beverly Trayner, "Communities of Practice: a brief introduction" pp. 8, V April 15, 2015, https://wenger-trayner.com/

[18] Adrianna Kezar, "Higher Education Change and Social Networks: A Review of Research," The Journal of Higher Education, vol. 85, no. 1, pp. 91-125, 2014, DOI: $\underline{10.1080 / 00221546.2014 .11777320}$

[19] Donald A. Schön, The Reflective Practitioner: How Professionals Think in Action. New York, NY: Basic Books, 1983.

[20] Glynis Cousin, Researching Learning in Higher Education: An Introduction to Contemporary Methods and Approaches. New York, NY: Routledge, 2009, pp. 259, ISBN: 9780415991643.

[21] Irving Seidman, Interviewing as Qualitative Research: A Guide for Researchers in Education and the Social Sciences. New York, NY: Teachers College Press, 2006, 162 pp.

[22] E. Wenger, B. Trayner, and M. de Laat, Promoting and assessing value creation in communities and networks: A conceptual framework. Heerlen, The Netherlands: Open University Press, 2011.

[23] Brenda K. Wiederhold, "Connecting Through Technology During the Coronavirus Disease 2019 Pandemic Avoiding "Zoom Fatigue"", Cyberpsychology, Behavior, and Social Network, vol. 23, no. 7, pp. 437-438, 2020, DOI: 10.1089/cyber.2020.29188.bkw

[24]John E. Cowan \& Michael P. Menchaca (2014) Investigating value creation in a community of practice with social network analysis in a hybrid online graduate education program, Distance Education, 35:1, 43-74, DOI: $10.1080 / 01587919.2014 .893813$ 